\title{
RANCANG BANGUN MEETING MANAGEMET SYSTEM BERBASIS MOBILE
}

\author{
Fitriani Bakri', Irawati² \\ ${ }^{1}$ fitriani_bakri@gmail.com, 2irawan2804@gmail.com \\ 1,2Universitas Muslim Indonesia
}

\begin{abstract}
Abstrak
Dalam sebuah instansi atau organisasi, manajemen informasi sangatlah penting, terutama ketika akan diadakan pertemuan dalam hal ini Rapat atau Meeting. Menjadwalkan sebuah rapat merupakan salah satu komponen tugas bagian Kantor Hubungan Masyarakat (HUMAS) dalam hal memberikan pelayanan administrasi dalam menyelenggarakan publikasi dan informasi baik internal maupun eksternal. Metode pengelolaan rapat yang digunakan sejauh ini masih menggunakan cara konvensional seperti penyampaian langsung atau berupa undangan tertulis kemudian disebar. Penyerahan surat undangan, SMS, atau telepon ini memiliki banyak kelemahan untuk itu masih diperlukan aplikasi yang memudahkan dalam penyebaran informasi tersebut. Dengan menerapkan Push notification dalam model data JSON API memiliki keunggulan yaitu pengguna tidak perlu melakukan request untuk mendapatkan informasi kegiatan yang ada. Informasi baru dari server Admin akan langsung dikirimkan kepada pegawai Universitas, dengan catatan bahwa perangkat Android bergerak harus dalam keadaan menyala dan terkoneksi dengan internet. Hasil yang diperoleh dalam penelitian ini, berupa aplikasi Android yang dapat menampilkan informasi daftar meeting, dan fitur notifikasi reminder bagi user yang akan selalu mengingatkan akan adanya meeting yang akan berlangsung berdasarkan inputan admin pada web app sebelumnya.
\end{abstract}

Kata kunci: Meeting, Push Notification, JSON API, Web App.

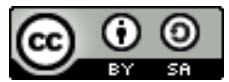

ILKOM Jurnal IImiah work is licensed under a CCA-SA 4.0 International License.

\section{Pendahuluan}

Rapat atau meeting adalah bagian dari kegiatan penting pegawai civitas kampus dalam Universitas Muslim Indonesia untuk merundingkan, membicarakan atau menyelesaikan suatu masalah yang menyangkut kepentingan bersama, atau membicarakan hal-hal yang berkaitan dengan perkembangan Universitas. Menjadwalkan sebuah rapat merupakan salah satu komponen yang sangat penting dalam hal memberikan pelayanan administrasi dalam menyelenggarakan publikasi dan informasi baik internal maupun eksternal. Metode pengelolaan rapat yang digunakan sejauh ini masih menggunakan cara konvensional seperti penyampaian langsung bagian unit yang memberikan permintaan rapat atau kegiatan internal, setelah itu permintaan akan diproses dan undangan rapat kemudian disebar. Cara penyebaran informasi tersebut dapat berupa penyampaian secara langsung, melalui mading, penyerahan surat undangan, SMS, atau telepon. Namun kelemahan dari cara ini yaitu masih diperlukan usaha yang besar dan memakan banyak waktu. Tidak menutup kemungkinan, dari cara penyebaran informasi yang sudah ada sekarang masih saja terdapat masalah-masalah teknis, seperti jadwal yang berubah-ubah dan informasi yang terlambat datang kadang masih tidak bisa dihindari, sehingga peserta meeting yang diundang ada yang tidak mengetahui informasi dan tidak sempat hadir mengikuti Rapat.

Sistem yang diusulkan adalah push notification. Push notification adalah pemberitahuan yang masuk secara instan pada perangkat bergerak Android menggunakan jaringan internet. Sistem ini berfungsi untuk menyampaikan informasi rapat yang melibatkan pegawai di Universitas dalam bentuk notifikasi secara langsung yang dikirim kepada pegawai peserta rapat, sehingga pegawai dapat mengetahui informasi rapat di Universitas yang melibatkan pegawai tersebut. Push notification memiliki keunggulan yaitu pengguna tidak perlu melakukan request untuk mendapatkan informasi kegiatan yang ada. Informasi baru dari server Admin akan langsung dikirimkan kepada pegawai Universitas, dengan catatan bahwa perangkat bergerak harus dalam keadaan menyala dan terkoneksi dengan internet.

Yang menjadi batasan masalah yaitu sistem ini dibangun dengan menggunakan Bahasa Pemrograman Web (HTML, PHP, CSS), dan push notification yang diterapkan kedalam smartphone android dimana penyampaian ini berupa informasi rapat (tempat, tanggal, jam, rincian rapat), aplikasi ini hanya menampilkan informasi meeting dan tidak memberikan komunikasi dua arah atau peserta 
meeting saat melakukan konfirmasi ketidakkehadiran.. Berdasarkan latar belakang permasalahan yang telah diuraikan maka dapat diambil rumusan yaitu bagaimana membangun sebuah aplikasi Meeting Management System berbasis Mobile untuk mempermudah mekanisme pengelolaan meeting sesuai dengan mekanisme meeting di Universitas Muslim Indonesia dan bagaimana pengaruh penerapan push Notification terhadap penyebaran Informasi pada aplikasi Mobile Management System. Aplikasi yang dibangun ini dapat membantu mekanisme pengelolaan rapat pada Universitas Muslim Indonesia yaitu dalam mengelola jadwal rapat yang lebih terorganisir dan dapat memudahkan penyebaran informasi serta memaksimalkan pemanfaatan teknologi dalam aktifitas-aktifitas pegawai civitas Kampus.

\section{LandasanTeori}

\subsection{GPS (Global Positioning System)}

GPS atau Global Positioning System adalah suatu sistem navigasi satelit yang terdiri dari 24 satelit beroperasi dan 3 satelit cadangan. Ke-24 satelit itu mengorbit bumi pada jarak $20.200 \mathrm{~km}$ dan waktu orbit 12 jam, sambil memancarkan sinyal berita gelombang radio. Departemen Pertahanan AS yang mengoperasikan sistem GPS telah mengatur konfigurasi satelit sedemikian rupa, sehingga semua tempat dibumi dapat menerima sinyal dari 4 sampai 10 satelit. Sebagai penunjuk waktu, masing-masing satelit dibekali dengan 4 buah jam atom yang dapat mengukur waktu dengan ketelitian sepermilyar detik. Teknologi GPS sanggup menentukan lokasi manapun dimuka bumi dengan ketelitian kurang lebih 1 meter [10].

\subsection{Website}

Website adalah suatu jaringan dair dokumen - dokumen elektronik yang disebut halaman web, yang isinya dapat berupa teks, grafis, dan bahkan format suara dan format video. Dokumendokumen tersebut terintegrasi dengan hyperlinks. Hyperlinks memungkinkan user untuk mendapatkan informasi yang diinginkan dari satu halaman ke halaman lainnya menggunakan link tersebut dengan mudah [6].

Website memiliki tiga komponen dasar:

a. Home Page

Home page merupakan awal yang muncul saat user mengakses suatu website. Home page dibuat untuk menciptakan kesan pertama user terhadap website.

b. Link

Penghubung antar web page yang digunakan oleh user untuk berpindah web page. Hal yang dapat dilakukan oleh link:

1. Membawa user ke web page lain dalam website yang sama atau website berbeda.

2. Memindahkan cursor ke posisi lain dalam web page tersebut.

3. Untuk mengunduh atau menduplikasi data dari website ke komputer user.

4. Menghubungkan user ke tempat lain dalam internet, seperti e-mail.

c. Content

Content merupakan bagian dari website, dan dapat berupa teks, gambar, suara, video, link, ke situs lain yang berkaitan.

\subsection{HTML (Hypertext Markup Language)}

HTML adalah dokumen yang mengatur bahasa-bahasa yang digunakan untuk mendesain kebanyakan halaman web. HTML adalah suatu sistem untuk marking-up, tagging, sehingga dokumen tersebut dapat dipublikasikan ke web [7].

\subsection{PHP (PHP Hypertext Protocol)}

PHP adalah bahasa pemrograman open source yang menempel pada HTML yang didukung oleh banyak web sever termasuk apacheHTTP server dan Microsoft's internet information server, dan pilihan bahasa pemrograman Linux web. Salah satu keuntungan dari PHP adalah dapat diperpanjang, dan nomor modul perpanjangannya sudah menyediakan dukungan seperti koneksi basis data, mail, dan XML [7].

\subsection{CSS (Cascading Style Sheets)}

CSS adalah suatu bahasa stylesheets yang mengatur tampilan suatun dokumen. Pada umumnya CSS digunakan untuk mengatur tampilan dokumen. CSS memungkinkan kita untuk menampilkan halaman yang sama dengna format yang berbeda.

Dengan CSS, tampilan website akan lebih cantik dan konsisten. Ada dua cara untuk menuliskan kode CSS. Pertama secara internal, yaitu menuliskan langsung diantara tag HTML/XHTML. Kedua secara eksternal, yaitu kode CSS disimpan dalam file yang terpisah kemudian dipanggil 
saat halaman web dibuka, CSS sendiri merupakan sebuah teknologi internet yang direkomendasikan oleh W3C (World Wide Web Consortium) dan diperkenalkan pada tahun 1996 [8].

\subsection{Google Maps}

Google Maps Meupakan layanan penyedia jasa informasi lokasi berupa peta, sehingga kemanapun anda ingin Pergi anda dapat dengan mudah mengakses lokasi tersebut dengan memanfaatkan fitur Google Maps yang berbasis Online. Namun jika anda ingin mengembangkannya dalam bentuk website maka anda harus memilliki fitur API Key yang menjadi kunci akses untuk pengembangan aplikasi (Developer) untuk aplikasi yang berbasis Maps maupun informasi lokasi selain daria API Key adapaun hal yang menjadi pokok dalam pengembangan Maps Google Adalah kordinat lokasi yang berbasis latitude dan longitude.

\subsection{Android}

Android adalah sistem operasi untuk telepon seluler yang berbasis Linux. Android menyediakan platform terbuka bagi para pengembang buat menciptakan aplikasi mereka sendiri untuk digunakan oleh bermacam peranti bergerak. Awalnya, Google Inc. membeli Android Inc., pendatang baru yang membuat peranti lunak untuk ponsel. Kemudian untuk mengembangkan Android, dibentuklah Open Handset Alliance, konsorsium dari 34 perusahaan peranti keras, peranti lunak, dan telekomunikasi, termasuk Google, HTC, Intel, Motorola, Qualcomm, T-Mobile, dan Nvidia.

Di dunia ini terdapat dua jenis distributor sistem operasi Android. Pertama yang mendapat dukungan penuh dari Google atau Google Mail Services (GMS) dan kedua adalah yang benarbenar bebas distribusinya tanpa dukungan langsung Google atau dikenal sebagai Open Handset Distribution (OHD) [10].

\subsection{Java}

Java dipelopori oleh James Gosling, Patrick Naughton, Chris Warth, Ed Frank, dan Mike Sheridan dari Sun Microsystems, Inc pada tahun 1991. Mereka membutuhkan kurang lebih 18 bulan untuk membuat versi pertamanya. Bahasa ini pada awalnya disebut "Oak" tapi kemudian diubah menjadi "Java" pada tahun 1995 karena nama Oak telah dijadikan hak cipta dan digunakan sebagai bahasa pemrograman lainnya. Antara pembuatan Oak pada musim gugur 1992 hingga diumumkan ke publik pada musim semi 1995, banyak orang yang terlibat dalam desain dan evolusi bahasa ini. Bill Joy, Arthur van Hoff, Jonathan Payne, Frank Yellin, dan Tim Lindholm merupakan kontributor kunci yang mematangkan prototipe aslinya.

Bahasa pemrograman lain yang telah ada sebelum Java lahir sudah merupakan bahasa yang baik dan mudah dipelajasi oleh programmer profesional. Akan tetapi para programmer ini menginginkan sesuatu yang baru yang memiliki banyak hal yang menyelesaikan masalah mereka. Utamanya adalah keamanan kode mereka. Hal ini melahirkan pikiran yang revolusioner untuk menemukan bahasa pemrograman lain yang disebut Java. Tidak hanya keamanan tapi juga beberapa hal yang sering disebut sebagai Java-Buzzwords. Kata-kata ini menjelaskan berbagai fitur tambahan dan beberapa hal yang membuat Java demikian sukses dan diterima oleh dunia perangkat lunak. Adapun ladasan mengapa penulis menggunakan java sebagai pembuatan aplikasi adalah sebagi berikut karene memiliki beberapa keuntungan yang dijabarkan sebagai berikut:

\subsection{Push Notification \& JSON API}

Mirip seperti SMS, push notification adalah pemberitahuan yang masuk secara instan pada ponsel Android atau iOS anda. Pemberitahuan down akan dikirim secara langsung (paksa/pushed) ke ponsel anda.

JSON (JavaScript Object Notation) adalah format pertukaran data yang ringan, mudah dibaca dan ditulis oleh manusia, serta mudah diterjemahkan dan dibuat (generate) oleh komputer. Format ini dibuat berdasarkan bagian dari Bahasa Pemrograman JavaScript, JSON merupakan format teks yang tidak bergantung pada bahasa pemprograman apapun karena menggunakan gaya bahasa yang umum digunakan oleh programmer keluarga $C$ termasuk $C$, C++, C\#, Java, JavaScript, Perl, Python dan lain-lain. Oleh karena sifat-sifat tersebut, menjadikan JSON ideal sebagai bahasa pertukaran data.

\section{Metode}


Dalam pengembangan sistem berarti, dapat menyusun suatu sistem yang baru untuk menggantikan sistem yang lama secara keseluruhan/ mengembangkan sistem yang telah ada. Maka metode pengembangan yang dilakukan yaitu metode waterfall.

Metode waterfall merupakan metode yang sering digunakan oleh penganalisa sistem pada umumnya. Inti dari metode waterfall adalah pengerjaan dari suatu sistem dilakukan secara berurutan atau secara linear. Jadi jika langkah ke-1 belum dikerjakan, maka langkah 2 tidak dapat dikerjakan. Jika langkah ke-2 belum dikerjakan maka langkah ke-3 juga tidak dapat dikerjakan, begitu seterusnya. Secara otomatis langkah ke-3 akan bisa dilakukan jika langkah ke1 dan ke-2 sudah dilakukan. Sebagai contoh tahap desain harus menunggu selesainya tahap sebelumnya yaitu tahap requirement. Berikut gambar model waterfall.

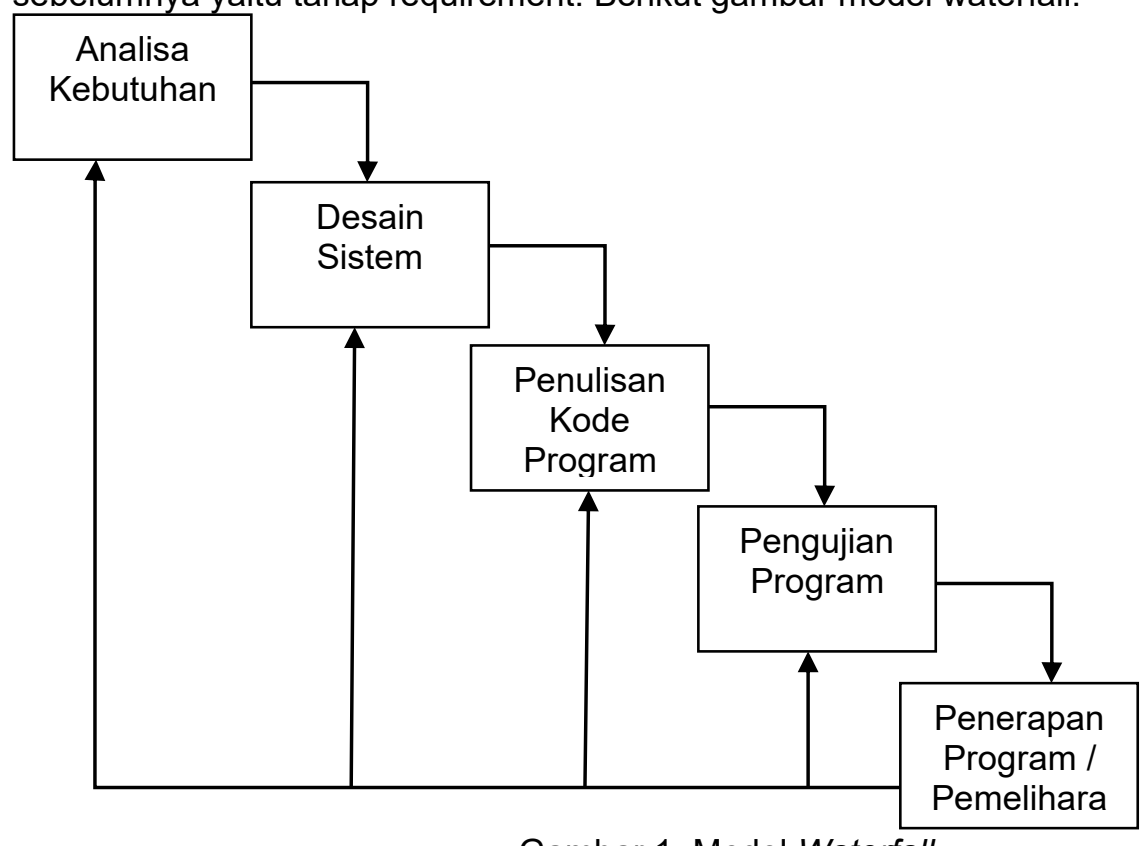

Gambar 1. Model Waterfall

Tahap-tahap metode waterfall yang dilakukan sebagai berikut :

a. Analisa Kebutuhan

Untuk pembuatan sistem dibutuhkan data yang diperoleh dari wawancara, pengamatan langsung dan studi literatur. Data inilah yang akan menjadi acuan penelitian untuk diterjemahkan kedalam bahasa pemrograman.

b. Desain Sistem

Melakukan perancangan perangkat lunak yang terdapat pada struktur data, arsitektur perangkat lunak, interface dan algoritma. Terdiri dari diagram yang menggambarkan sistem secara keseluruhan, antara lain use case diagram, class diagram, sequence diagram, dan diagram lainnya.

c. Penulisan Kode Program

Merupakan tahap penerjemahan desain kedalam bahasa pemrograman. Coding dilakukan menggunakan Dreamweaver, android SDK dan desain menggunakan Adobe Photoshop.

d. Pengujian Sistem

Tahapan akhir dimana sistem yang baru diuji kemampuan dan keefektifannya sehingga dapat menemukan kesalahan-kesalahan dan mengetahui apakah semua fungsi perangkat lunak telah berjalan. Kemudian dilakukan pengkajian ulang dan perbaikan terhadap aplikasi menjadi lebih baik dan sempurna menggunakan teknik blackbox.

e. Penerapan dan Pemeliharaan

Tahapan ini bisa dikatakan final dalam pembuatan sebuah sistem. Setelah melakukan analisa, design dan pengkodean maka sistem yang sudah jadikan digunakan oleh user.

Tahapan pemeliharaan dilakukan jika aplikasi mengalami masalah dan perkembangan kebutuhan fungsional.

Berdasarkan hasil pengamatan, penulis kali ini akan membuat sebuah aplikasi meeting dengan memanfaatkan teknik push notification dan JSON API guna mengirimkan informasi secara langsung ke dalam aplikasi smartphone yang berbasis android. Setiap informasi meeting yang ditambahkan secara otomatis info tersebut akan disampaikan dan mengirim pesan notifikasi kedalam aplikasi android yang dibuat. 
Informasi yang disampaikan dikirim melalui internet dengan isi informasi berupa title meeting, waktu, tanggal, lokasi dan detail informasi meeting yang dapat dilihat user melalui aplikasi. Selain dari informasi tersebut juga akan ditampilkan peta lokasi meeting sehingga membantu jika user ingin menuju lokasi dengan bantuan penunjuk arah menuju lokasi meeting. Untuk lebih jelasnya sistem yang dibuat dapat dilihat dalam gambar berikut ini:

Peta Lokasi Meeting

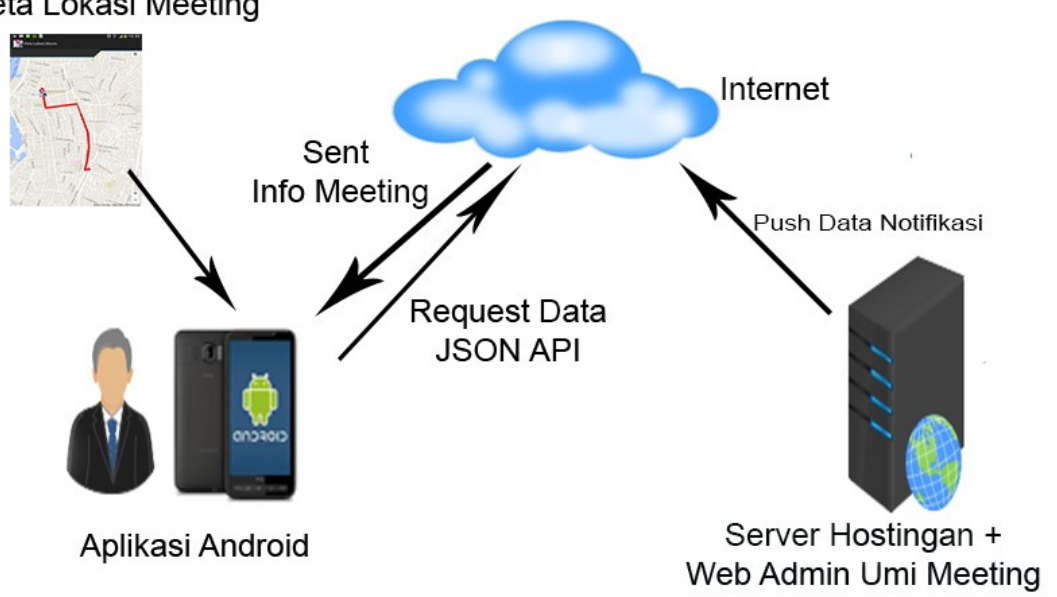

Gambar 2. Gambar Aliran Sistem Di Usulkan

Berdasarkan gambar 2 ketika rancangan konsep dari aplikasi yang akan dibuat telah selesai, maka tahapan dalam perancangan lainnya adalah dengan menggambarkan case atau kegiatan-kegiatan yang akan dilakukan oleh user ataupun admin aplikasi kedepannya. Untuk lebih jelasnya pengembangan dari aplikasi digambarkan dalam uml dalam bentuk use case diagram seperti berikut:

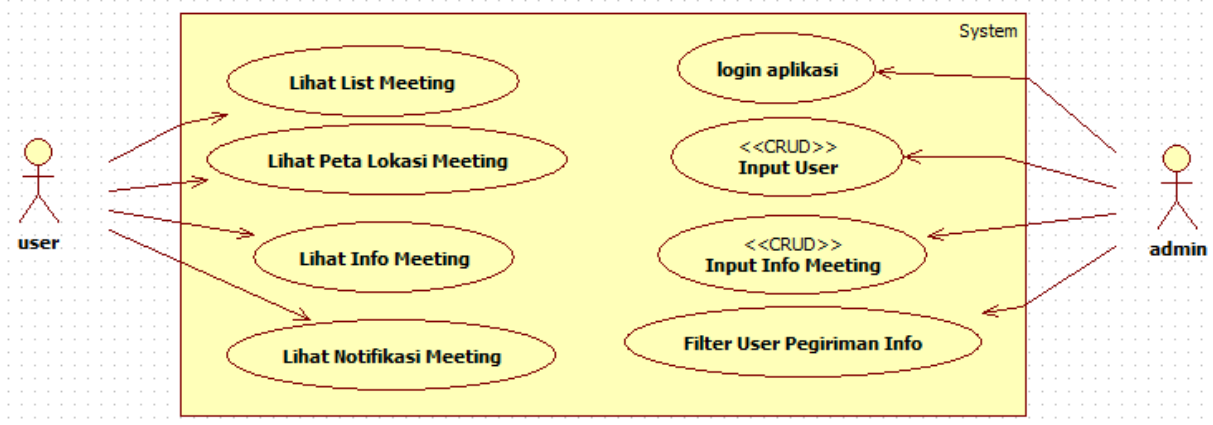

Gambar 3. Gambaran Use Case Aplikasi Yang Akan dibuat

Terlihat dari gambar use case diatas bahwa user dapat melihat list meeting yang akan datang, lihat info meeting seperti lokasi, waktu, dan tempat meeting, dan mendapatkan notifikasi dari aplikasi yang digunakan. Sedangkan admin berperan dalam melakukan pendaftaran user, menambahkan meeting, dan mampu filterisasi yang berguna untuk mengatur siapa saja yang akan menerima pesan meeting yang di inputkan.

\section{Hasil}

\subsection{Memulai Aplikasi Android}

Untuk memulai aplikasi sebaiknya telah mendaftarkan email yang digunakan dalam smartphone. Email yang ada dalam smartphone akan digunakan sebagai authentikasi dalam pengguna aplikasi UMI Meeting. Berikut proses login kedalam interface aplikasi android. 


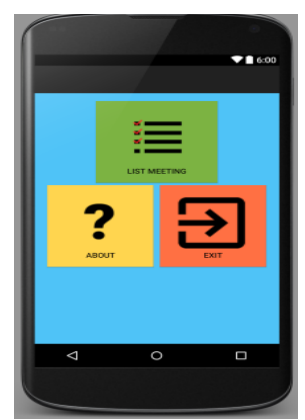

Gambar 4. Memulai Aplikasi Android

\subsection{Interface Menu Utama Web App}

Form ini menggambarkan menu-menu utama aplikasi web app yang dibuat. Menu utama ini akan menampilkan fitur menu meeting untuk membuat meeting, dan user untuk mendaftarkan user kedalam sistem yang akan menerima pemberitahuan rapat. Untuk lebih jelasnya dapat digambarkan sebagai berikut :

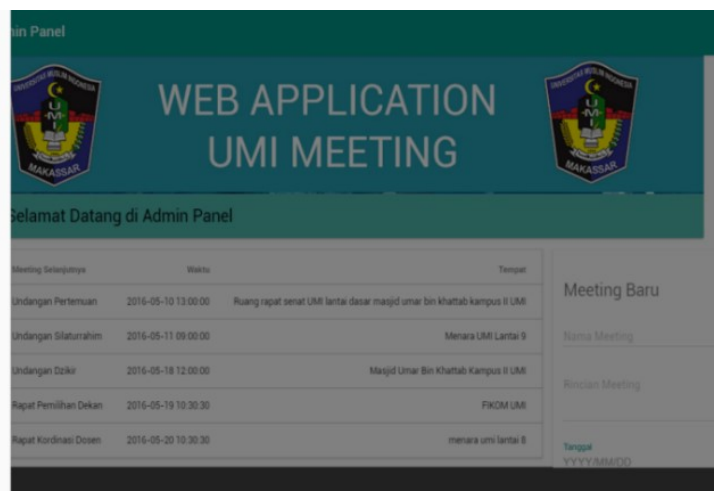

Gambar 5. Menu Utama Web App

\subsection{Interface Form Meeting}

Form ini digunakan untuk membuat meeting yang ada dengan terlebih dahulu mengisi data meeting yang diperlukan seperti judul, rincian, lokasi, waktu, tanggal meeting. Untuk lebih jelasnya digambarkan sebagai berikut :

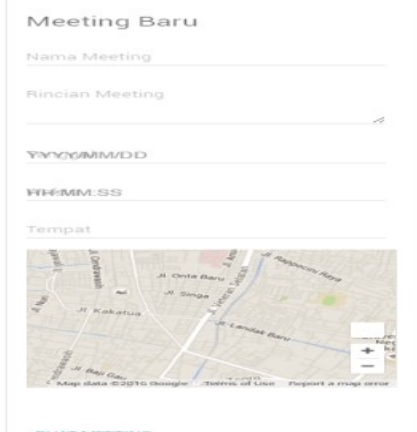

Gambar 6. Interface form Input Meeting

Setelah data meeting di isikan maka akan tampil dalam bentuk tabel yang berisi daftar meeting yang dibuat. Dari desain ini memperlihatkan beberapa tombol yang digunakan antara lain tombol edit, delete dan tombol untuk melakukan filterisasi data user yang mana saja akan menerima notifikasi. Untuk lebih jelasnya dapat dilihat dalam gambar berikut ini :

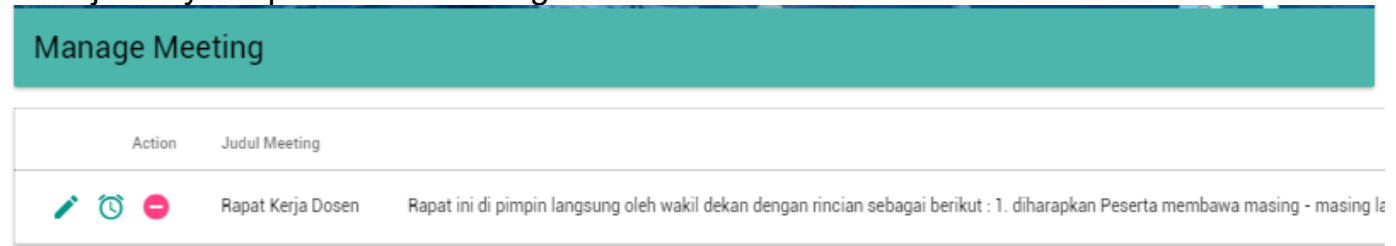

Gambar 7. Tabel Manage Meeting 


\subsection{Interface Form Filterisasi User}

Merupakan interface untuk melakukan filterisasi atau pemilihan kepada user yang mana saja akan disampaikan notifikasi dan reminder meeting. Untuk lebih jelasnya dapat melihat gambar berikut:

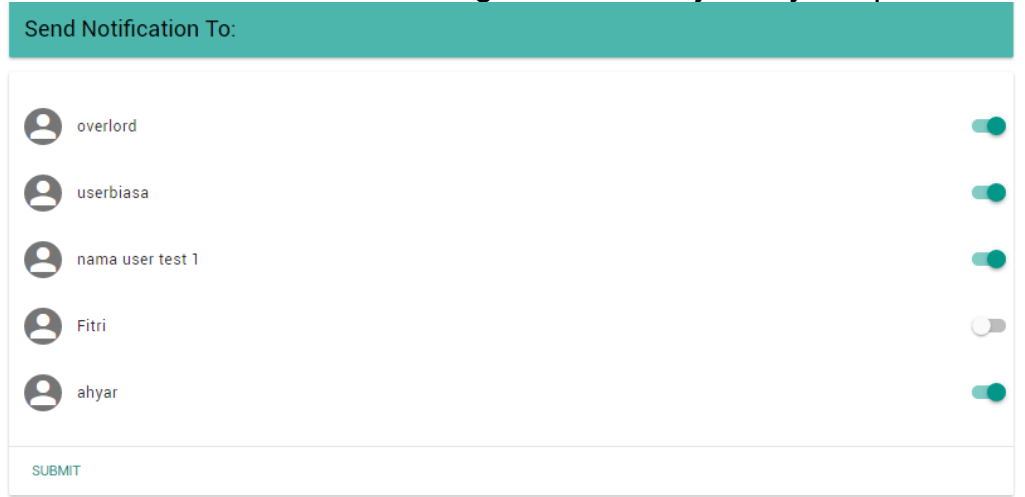

Gambar 8. Form Filterisasi User

\subsection{Interface Penunjuk Arah Aplikasi Android}

Merupakan interface yang ditampilkan saat telah menekan tombol penunjuk arah di detail maps detail meeting. Aplikasi akan menampilkan peta dengan penunjukan arah berdasarkan keberadaan memanfaatkan GPS yang ada pada smartphone ditandai marker biru. Dalam penunjuk arah ini juga terlihat warna jalur yang digunakan menuju lokasi meeting yang ditandai dengan warna merah. untuk lebih jelasnya aplikasi dapat dilihat dibawah ini:

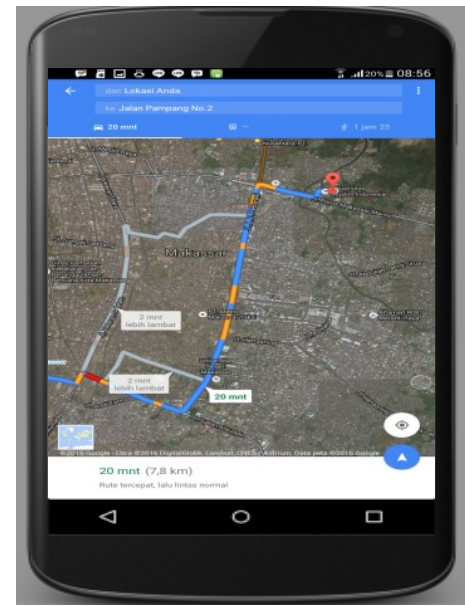

Gambar 9. Interface Penunjuk Arah Meeting Android

\section{Kesimpulan dan Saran}

\subsection{Kesimpulan}

Setelah melakukan pengujian terhadap aplikasi ini maka dapat ditarik kesimpulan sebagai berikut:

a. Aplikasi ini dibangun dengan menggunakan fitur push notification dengan data reminder yang dikirimkan dari server sesuai dengan user yang sebelumnya telah register dalam web app sebelum menggunakan aplikasi android.

b. Pengaruh penerapan Push Notification terhadap penyebaran informasi dapat langsung dirasakan dengan melihat reminder pengingat meeting yang sampai kepada semua user yang sebelumnya telah di filterisasi

c. Fitur yang dimiliki aplikasi ini adalah fitur penyampaian meeting mulai dari rincian meeting, waktu, tanggal, tempat meeting beserta lokasi meeting yang disampaikan dalam model peta Google Maps.

d. Fitur lainnya yang dimiliki aplikasi ini adalah penunjuk arah menuju lokasi meeting sehingga memudahkan dalam mencari lokasi meeting secara langsung melalui smartphone.

e. Admin memiliki peranan penting dalam mengatur jadwal meeting dan melakukan filterisasi (mengatur siapa saja user yang akan menerima reminder meeting).

\subsection{Saran}


Dari kesimpulan diatas, maka penulis meberikan saran-saran yang kiranya dapat dipertimbangkan untuk pengembangan aplikasi berikutnya. Adapun saran-saran penulis dalam penelitian ini adalah sebagai berikut :

a. Program aplikasi mobile Rancang Bangun Meeting Managemet System berbasis Mobile sebaiknya ketika digunakan haruslah mengaktifkan GPS perangkat agar posisi keberadaan dapat terupdate sebelum menekan tombol penunjuk arah.

b. Pada aplikasi mobile Rancang Bangun Meeting Managemet System berbasis Mobile sebaiknya menggunakan android dengan sistem operasi minimal Ice Cream agar fitur fitur dari aplikasi dapat berjalan dengan baik.

\section{Daftar Pustaka}

[1] Asri, Aisar. 2014."Aplikasi Pengeolahan Jadwal Meeting Berbasis SMS Gateway".

[2] Achmad, Nadim.2015."Pengaruh Penerapan Push Notification terhadappenyebaran Informasi”.https://prezi.com/3nqielrqejpe/pengaruh-penerapan-push-notification-terhadapenyebaran-inf/.25 Januari 2016.

[3] Hikigaya. 2015."Pengenalan Google Cloud Messaging”.http://dnakreatif.com/cloud/pengenalangoogle-cloud-messaging-gcm/.25 Januari 2016.

[4] Nuradyanto, Dimas Nugroho., et al. 2014."Rancang Bangun Mobile Learningdengan push Notification System Berbasis protocol UDP pada perangkat Blackberry".

[5] Putra, Kadek A.M., et al. 2013."Pengembangan Aplikasi Daftar perencanaanKegiatan Berbagi Pakai pada Sistem Operasi Android”.

[6] Coupey, Eloise. 2001. "Marketing and the Internet". New Jersey : Prentice Hall, New Jersey.

[7] Connolly, T. dan Begg, C. 2005 "Database Systems: A Practical Approach to Design, implementation, and Management. (4th edition)", Addison Wesley,USA.

[8] Sulistyawan., Rubianto., Rahmad Saleh. 2008. "Modifikasi Blog Multiply dengan CSS". Jakarta: Elex Media Komputindo

[9] J.Poulcheria Benou, Costas Vassilakis. 2010. "A context management architecture for mcommerce applications", Springer Journal of Computer Science June 2012, Volume 2, Issue 2,

[10] Nazruddin. 2011. "Android Pemrograman mobile smart phone \& Tablet PC". Bandung : Informatika.

[11] Janner Simarmata. 2010. "Rekayasa Perangkat Lunak". Jakarta: Andi Publisher.

[12] Suhendar A \& Gunadi Hariman. 2008. "Mastering UML with rational Rose 200". Jakarta: Informatika

[13] https://support.google.com/maps/answer/3092426?hl=en\&ref_topic=3092425 (diakses Tanggal 10 April 2016 Pukul 20.00 WITA). 